\title{
Las Américas y el proceso electoral 2008 de Estados Unidos
}

\author{
Asmara González Rojas•
}

Las Américas de cara al proceso electoral de los Estados Unidos 2008 se centra, como el título sugiere, en el análisis de las posturas de América Latina frente a un proceso electoral estadounidense, mismo que en 2008 toma matices distintos e inéditos, que levantan múltiples expectativas para nuestra región; en esto va implícita cierta probabilidad de cambio en una relación históricamente conflictiva, marcada por la dependencia económica y la defensa de la soberanía.

¿Cómo entender el proceso político electoral estadounidense? ¿Cómo ha sido el devenir latinoamericano y cómo puede ser afectado por las perspectivas de uno y otro candidato? ¿Cuáles esferas determinan la diferencia o la similitud entre el proyecto republicano de John McCain y el del demócrata Barack Obama? ¿Es el cambio o la continuidad de la política exterior estadounidense hacia la región lo que trazará la agenda del nuevo presidente estadounidense? Son interrogantes que se plantean los autores de este libro coordinado por Ignacio Medina y Jaime Preciado, ambos estudiosos y conocedores de las problemáticas latinoamericanas, que una vez más aportan al entendimiento y estimulan la discusión sobre los debates actuales en la región.

Jaime Preciado, Ignacio Medina (coords.) (2008), Las Américas de cara al proceso electoral de los Estados Unidos 2008, Argentina, El aleph. 
Este libro incluye panorámicas distintas que se organizan en nueve ensayos que puntualmente analizan lo siguiente. Primero, "Procesos electorales y política latinoamericana de Estados Unidos: algunas claves metodológicas para su análisis” de Jorge Hernández Martínez. Segundo, "Un balance de la política estadounidense hacia América Latina; escenarios del proceso electoral presidencial de 2008" de Jaime Preciado y Pablo Uc. Tercero, "La administración Bush y América Latina: Un análisis preliminar" de Gary F. Prevost. Cuarto, "La retórica del odio del movimiento antiinmigrante y las perspectivas de cambio ante las elecciones del 2008 en los Estados Unidos” de Hugo Méndez Ramírez. Quinto, "Lecciones inacabadas: integración, cooperación y desarrollo en América Latina y el Caribe" de Feliciano García Aguirre. Sexto, "Reformas económicas y políticas en Cuba y perspectivas frente a una nueva administración estadounidense” de Emilio Duharte Díaz. Séptimo, “Alternativas de América Latina frente al proceso electoral de Estados Unidos” de Lino Borroto López. Octavo, “¿Qué puede esperar América Latina de la próxima administración estadounidense?" de Carlos Oliva Campos. Noveno, "Diversas visiones sobre Norteamérica" de Ignacio Medina Núñez. Por cuestión de espacio no reviso todos los autores a profundidad, pero procuro dar una panorámica general sobre los puntos de acuerdo entre ellos.

Un punto central del libro es analizar las estrategias de campaña hacia AL seguidas por McCain y Obama, al mismo tiempo incluyen y analizan las percepciones de autores estadounidenses sobre el tema, lo cual nos permite tener una visión mucho más amplia. Cada autor lo hace con su bagaje intelectual y desde su disciplina - la sociología y las relaciones internacionales-, y todos ellos demuestran un amplio conocimiento de la problemática latinoamericana y su relación con Estados Unidos. 
Otro punto que destacar es que casi todos los autores coinciden que América Latina tiene hoy la potencialidad de tomar las riendas de su propio destino a través de proyectos alternativos a la visión estadounidense. La sociedad tiene cada vez más una posición de contrapeso al Estado.

Destaco algunos comentarios sobre los siguientes ensayos.

"Procesos electorales y política latinoamericana de Estados Unidos: algunas claves metodológicas para su análisis" de Jorge Hernández Martínez

El artículo inicial de Jorge Hernández Martínez emprende un análisis histórico-concreto sobre el papel latinoamericano en la política y procesos electorales de Estados Unidos. Hace un recuento importante de los elementos y factores que los estadounidenses han incluido en su política exterior hacia la región. Para poder llegar a conclusiones actuales, el autor parte de un análisis sociopolítico sobre las características del sistema político y electoral de Estados Unidos, destacando la formación de las ideas políticas de Estados Unidos desde 1776 con la declaración de independencia. Lo anterior, en el marco de entender la trascendencia del proceso electoral presidencial de 2008, cuando se conjugaron elementos inéditos en la historia política de dicho país.

Habla de la lógica del sistema político estadounidense, que se basa en la ideología del WASP, —y yo agregaría, del American creed y de su carácter excepcional-. Posturas que debemos tomar en cuenta para entender la composición social y política de Estados Unidos, mismas que han estado en constante debate con la idea del American dream y el discurso de igualdad de oportunidades versus las problemáticas de racismo, intolerancia, superioridad étnica y religiosa, así como el individualismo. 
Destaca que el proceso electoral del 2008 y significativamente la presencia de Barack Obama generan expectativa sobre un posible cambio en la continuidad de la política exterior de Estados Unidos para América Latina, que en la post-guerra fría han estado marcadas por la visión globalista "de raíz geopolítica que encuadra situaciones mundiales en el marco de la supuesta lucha contra el terrorismo, priorizando los intereses de la llamada seguridad nacional, con implicaciones para el tratamiento de las relaciones con los países del subcontinente, y fundamentalmente, para la evolución de determinados conflictos, estimulando tensiones y enfrentamientos". Hay muchos ejemplos; la construcción del muro fronterizo México-EU, el Plan Colombia, la hostilidad hacia Venezuela y Bolivia, junto con la prolongada guerra fría hacia Cuba, ilustran la existencia de un clima de polarización.

Jorge Hernández analiza y enfatiza consideraciones históricas para entender las situaciones actuales dentro de la coyuntura de las elecciones de 2008.

Primero, no debemos olvidar que Estados Unidos se consolida como primera nación moderna que ejemplifica el modelo democrático como base de su sistema político, independiente de cualquier nexo colonial. Segundo, hace un breve recuento de la formación de las ideas políticas y ejemplifica — aunque no lo dice con estas palabras - el doble discurso de la política estadounidense. Tercero, aborda el tema de la hegemonía, que sin duda se refuerza a partir de la posguerra, y entra al debate sobre la crisis de dicha hegemonía post-guerra fría con la idea de multilateralismo, aunque reconoce que no podemos dar por muerta la supremacía de EU, sobre todo después de los atentados del 11 de septiembre de 2001, en la región latinoamericana, incluso a pesar del avance de la izquierda en AL. Sin embargo, puntualiza que la supremacía actualmente está concebida no en términos ideológicos sino cada vez más pragmáticos:

\section{6}


económicos, comerciales y de explotación de recursos que les ofrecen su "patio trasero". Cuarto, el autor no deja de lado el debate sobre la crisis de la identidad nacional de ese país que intenta seguir homogenizando a una población que se debe regir por el American creed y que enfatiza los asuntos de la realpolitik: beligerante, conservador, vertical; también habla de la nueva expresión del conservadurismo — conocidos como neoconservadores- de la doctrina Bush.

Finalmente, hace un recuento de cómo la política exterior es un elemento crucial para las elecciones norteamericanas e incluye la visión de estadounidenses especialistas en Latinoamérica; sintetiza sus posturas sobre la región, dentro de lo que destaca el ya lugar común de que América Latina no es hoy prioridad para Estados Unidos. Incluso el autor le da el beneficio de la duda a Obama, diciendo que una línea sobre AL en el discurso de toma de posesión abriría la puerta al cambio, cosa que desde luego no sucede. Analiza las constricciones de los políticos respecto a su relación entre lo local y lo nacional. Finalmente, hay una unión de los partidos tanto republicanos como demócratas, existen consensos básicos en torno a la política exterior. Sobre lo local, los limitan los grupos de interés.

Post guerra fría, los temas de la agenda AL-EU se han traducido en seguridad, narcotráfico. Post-11/09/2001, hablamos de seguridad hemisférica y guerra contra el terror. Sin embargo en estos temas no hay acuerdos entre EU y AL. Para el primero seguirán siendo temas prácticos sobre seguridad y libre comercio, así como utilización de recursos; para los segundos, temas vinculados al desarrollo, soberanía, superación de la pobreza, independencia, gobernabilidad y democracia.

Por otro lado, a comienzos del siglo XXI, la táctica de la formulación de enemigos ha visibilizado el debilitamiento y rechazo entre la sociedad internacional de la hegemonía de EU, y particularmente el rechazo de los latinoamericanos 
al Consenso de Washington, al neoliberalismo, y dobles discursos de democracia y derechos humanos contra los cuales hoy AL busca alternativas.

\section{"Un balance de la política estadounidense hacia AL; escenarios del proceso electoral presidencial del 2008” de Jaime Preciado y Pablo Uc}

Los autores hacen una revisión crítica y puntual de la política exterior de EU hacia la región. Analizan y confirman, a través de hechos contundentes (cifras, eventos, planes de acción, discursos), las visiones que tanto los estadounidenses como los latinoamericanos tienen sobre la política exterior hacia la región, ahondando en ejemplos de países representativos de la relación como lo son México, Colombia, Venezuela y Brasil, sin dejar de lado una breve reflexión en torno a Bolivia y Ecuador, así como el contexto de su posición actual.

Este artículo presenta una estructura muy ordenada de cosas que deben ser desarrolladas y analizadas a profundidad, sobre todo respecto a las hipótesis sobre las alianzas, asunto que seguramente Jaime Preciado abordará en su próximo libro.

Formula hipótesis muy claras que podrán comprobarse en la medida que avancen los días de Obama en la Casa Blanca. Sin embargo, el texto deja en claro una condición de larga duración que se verifica en hechos pasados y presentes.

Actualmente no depende sólo del proyecto estadounidense, sino también ( $y$ en creciente medida) de la opción y proyección política que América Latina decida otorgar a la relación. Por lo cual, la continuidad o el cambio de la política exterior estadounidense que se impulse a partir de enero de 2009, tendrá condiciones y límites que la historia interamericana no registra en su memoria política (Preciado y Uc, 2008: 83). 
El texto articula una serie de temáticas indispensables para los internacionalistas y estudiosos latinoamericanos, utiliza datos empíricos y sin duda invita al debate, a la reflexión y sugiere líneas de análisis para desarrollar.

\section{"La administración Bush y América Latina: una análisis preliminar" de Gary F. Prevost}

Prevost hace un recuento sobre la incidencia de Bush en AL a finales de su mandato. Habla sobre el interés que se tenía en el ALCA y como todo este proyecto no prosperó, entre otras cosas, por el 9/11/2001. Después de un análisis de los eventos, cumbres y reuniones internacionales de la región, el autor concluye en el mismo tenor que otros: "Si Latinoamérica busca hacerse un futuro diferente de su pasado de dominación, particularmente de la más reciente que viene de los Estados Unidos, debe buscar un desarrollo exitoso y sostenible que le permita tomar sus propias decisiones en el siglo XXI" (p. 98).

Otras visiones referentes a situaciones particulares serían, por ejemplo, las de Hugo Méndez, quien aborda los movimientos anti-inmigrante y las perspectivas de cambio ante las elecciones de 2008. Introduce la idea de entender a EU como un país de inmigrantes, y explica los ires y venires de la población hispana, que va en busca del American dream. Concluye haciendo un muy interesante análisis del discurso en torno a las Américas por parte de republicanos y demócratas, concluyendo que existen fuerzas contradicciones y dobles discursos en cuanto a la libertad para los hispanos.

"Diversas visiones sobre Norteamérica" de Ignacio Medina, es una mirada histórica sobre la formación de la nación estadounidense y sus relaciones con América Latina. Este artículo es muy interesante puesto que rescata ideas planteadas por varios autores clásicos estudiosos de 
Norteamérica en diferentes etapas. Entonces nos permite darnos cuenta de la evolución sobre las percepciones y apreciaciones que en cada momento determinados autores hicieron sobre la región y su relación con el resto del continente: desde las observaciones de Francisco de Miranda (1783-1784), Humboldt (1769-1859), Alexis de Tocqueville (1805-1859), Robert Putnam (finales del siglo XX); así como Galeano, González Casanova y Petras, que observan desde un ángulo más actual.

Me parece que es una buena forma de acercarse, con visión crítica, a las políticas exteriores de Estados Unidos y las relaciones interamericanas, reconociendo al mismo tiempo la congruencia en el doble discurso estadounidense hacia la región, hasta cierto punto la admiración sobre un sistema democrático, mismo que Tocqueville exaltaba; pero al mismo tiempo, examinando la continuidad de las políticas exteriores que desde la Doctrina Monroe de 1823 hasta la tan desdeñada Doctrina Bush, plantean la supremacía de Estados Unidos sobre la región como líder económico, militar y moral.

La hipótesis que apunta Ignacio Medina se inserta en la tónica de los ensayos que conforman este libro: Barack Obama no cambiará radicalmente la política exterior basada en una agenda vertical o de high politics de corte neo-realista. Es posible que incorpore elementos de soft power y se mueva como lo hizo en su momento Clinton con un discurso multilateral. Las propuestas de republicanos y demócratas pueden tener sentido en el plano interno, pero en lo externo en ambos partidos hay un consenso de continuar y reforzar el imperialismo y la supremacía estadounidense. Posterior a este ensayo, basta leer el discurso de toma de posesión de Obama para constatarlo.

Seguimos siendo la nación más próspera y poderosa de la Tierra [...] Nuestros padres fundadores elaboraron una Constitución sometida 
al imperio de la ley y a los derechos humanos, una norma que se ha perpetuado generación tras generación. Aquellos ideales aún iluminan el mundo, y no renunciaremos a ellos por intereses turbios [...] Así, digo a todos los demás pueblos y gobiernos que nos observan hoy, desde las grandes capitales hasta el pequeño pueblo donde nació mi padre: sepan que Estados Unidos es amigo de cada nación y de cada hombre, mujer y niño que busca un futuro de paz y dignidad, y que estamos dispuestos a ejercer nuestro liderazgo una vez más (El País, enero, 2009)

Medina apunta también que:

Las perspectivas para Latinoamérica seguirán estando más en sus propios procesos internos: en la disyuntiva de continuar siendo el patio trasero con sus consecuencias conocidas o en la búsqueda de variadas formas de resistencia y autonomía nacionales en proyectos alternativos al ALCA y a los tratados bilaterales, que de hecho ya se están desarrollando en el contexto de gobiernos como el de Venezuela, Bolivia, Argentina y Brasil (Medina, 2008: 246).

Este es un libro cuyas formulaciones son parte de un seminario que realizó la Red de Investigación sobre la Integración de América Latina y el Caribe (Redialc) en agosto de 2008 en Guadalajara, México, por lo tanto los textos no incluyen en su análisis el triunfo de Barack Obama. Se sabía que era el candidato más fuerte pero debido a la composición del sistema electoral estadounidense, se debía tener precauciones. Un paso esperado será seguir con el análisis de la administración de Obama y los demócratas, quienes desde luego en los primeros 100 días en función asumieron como prioridad las cuestiones económicas y financieras nacionales y globales. Hasta el día de hoy — como bien los mencionan los autores- AL esta ahí sin mucha preocupación por parte de EU, más que en el sentido comercial y pragmático, seguimos siendo vistos como suministradores de recursos naturales. 
Por otro lado, veo difícil que con las múltiples crisis - económica, social y de identidad - que atraviesa EU, las relaciones interamericanas tomen un nuevo sentido; aunque pareciera que Obama, por ser afroamericano, debiera tener mayor sensibilidad social hacia los inmigrantes hispanos y hacia la región, será muy difícil romper con el establishment - Mills lo plantea admirablemente- que firmemente se sustenta en los valores del American creed y que el mismo Barack Obama reafirmó en su toma de posesión al exaltar la grandeza de los padres fundadores y la solidez de su proyecto nacional, desde el comienzo.

Coincido plenamente con los autores en que AL debe tomar caminos alternos, adecuados a sus condiciones socioeconómicas y culturales. En la persecución de esta idea están inmersos ya varios Estados latinoamericanos, mismos que sin duda tienen detrás una producción académica de innumerables autores que estudian la región, los autores de este libro se suman a este grupo, notablemente en Guadalajara Jaime Preciado, Nacho Medina y los colegas del DEILA. Este libro, sin duda, es pertinente y recomendable para los internacionalistas y estudiosos de las ciencias sociales, así como para todo el público que se interese en las problemáticas americanas. 